•生物编目・

\title{
钱江源国家公园叶附生苔类植物的物种多样性
}

\author{
白 杨 ${ }^{1}$ 陈声文 ${ }^{2}$ 钱海源 ${ }^{2}$ 余顺海 ${ }^{2}$ 徐谊明 ${ }^{2}$ 张芷昕 ${ }^{1}$ \\ 沈 超 ${ }^{1}$ 陈雨奇 ${ }^{1}$ 张美琪 ${ }^{1}$ 余建平 ${ }^{2 *}$ 朱瑞良 ${ }^{1,3^{*}}$ \\ 1 (华东师范大学生命科学学院, 上海 200241) \\ 2 (钱江源国家公园管理局, 浙江开化 324300) \\ 3 (浙江天童森林生态系统国家野外科学观测研究站, 上海 200241)
}

\begin{abstract}
摘要: 本文报道钱江源国家公园叶附生苔类植物 4 科 9 属19种, 较之前记录增加3科8属17种。与钱江源处于同纬度 的我国其他地区相比, 钱江源叶附生苔类植物的种数仅次于西藏墨脱, 排名第二。鳞叶病鳞苔(Cololejeunea longifolia) 和尖叶薄鳞苔(Leptolejeunea subacuta) 是钱江源国家公园最常见的 2 种叶附生苔类植物。丰富的叶附生苔 类植物表明钱江源国家公园具有较合适的叶附生苔类植物生长环境, 这可能与该地区长期有效的保护密切相关。
\end{abstract}

关键词: 苔藓植物; 气候变暖; 黄山-怀玉山; 北纬29度; 叶附生苔

\section{Species diversity of epiphyllous liverworts in Qianjiangyuan National Park, Zhejiang}

Yang Bai ${ }^{1}$, Shengwen Chen ${ }^{2}$, Haiyuan Qian², Shunhai $\mathrm{Yu}^{2}$, Yiming $\mathrm{Xu}^{2}$, Zhixin Zhang ${ }^{1}$, Chao Shen ${ }^{1}$, Yuqi Chen $^{1}$, Meiqi Zhang ${ }^{1}$, Jianping $\mathrm{Yu}^{2 *}$, Ruiliang Zhu ${ }^{1,3^{*}}$

1 School of Life Sciences, East China Normal University, Shanghai 200241

2 Qianjiangyuan National Park, Kaihua, Zhejiang 324300

3 Tiantong National Station for Forest Ecosystem Research, East China Normal University, Shanghai 200241

\begin{abstract}
Nineteen species, belonging to nine genera in four families, of epiphyllous liverworts from Qianjiangyuan National Park are reported. Among them, 17 species belonging to eight genera in three families are newly reported. Compared with other areas of China with the same latitude, the number of species in Qiangjiangyuan National Park is the second only to Motuo of Xizang (Tibet). Cololejeunea longifolia and Leptolejeunea subacuta are most common species. The rich diversity of species indicates that the environment of Qianjiangyuan National Park is suitable for the growth of epiphyllous liverworts, which may be due to the long-term effective protection of the area.
\end{abstract}

Key words: bryophyte; climate warming; Huangshan-Huaiyushan; 29 degrees north latitude; epiphyllous liverwort

叶附生苔类植物(以下简称为叶附生苔)是指附 生于维管植物叶片表面的苔类植物, 是苔藓植物中 最为复杂的一个分类群(Benavides \& Sastre-De Jesús, 2011)。它们普遍存在于热带雨林, 在常绿阔 叶林中也有分布(陈邦杰和吴鹏程, 1964), 不仅具有 固氮、水分截留等重要的生理生态功能, 在指示气 候和森林变化方面也有重要作用(姜炎涁和邵小明, 2016)。钱江源国家公园地处浙江西部开化县, 北接
安徽, 西邻江西, 是我国生物多样性保护优先区域 “黄山一怀玉山”的关键区域、我国首批10个国家公园 体制试点区之一, 也是长三角经济发达区唯一的国 家公园体制试点区。古田山国家级自然保护区和钱 江源国家森林公园是该公园两大核心区域。1992年 和1993年华东师范大学田春元等曾对古田山自然 保护区的苔藓植物区系作了较为全面的调查, 曾报 道古田山自然保护区共有苔藓植物325种, 其中苔 
类植物有 22 科 39 属 89 种, 藓类植物有 33 科 103 属 236 种, 但未有叶附生苔的记载(田春元等, 1999)。虽然 地处钱江源国家公园核心区域的古田山自然保护 区早在1975年就已建立, 但对该地区的叶附生苔了 解甚少, 迄今为止唯一的报道是朱瑞良和苏美灵在 Epiphyllous Liverworts of China中报道了1属2种 (Zhu \& So, 2001)。为了全面揭示钱江源国家公园 体制试点区的苔藓物种多样性, 本文作者在前期 报道的基础上，于2018年和2019年两次前往钱江 源国家公园, 对叶附生苔类植物进行了全面调查, 增加了叶附生苔3科8属17种, 并与同纬度地区作比 较, 讨论其分布特点, 为我国叶附生苔资源的保护 提供参考。

\section{研究方法}

\section{1 研究区域}

钱江源国家公园由南向北依次覆盖苏庄、长虹、 何田、齐溪 4 个乡镇。其地理坐标为 $29^{\circ} 14^{\prime}-29^{\circ} 24^{\prime} \mathrm{N}$, $118^{\circ} 06^{\prime}-118^{\circ} 20^{\prime} \mathrm{E}$ ，属于白际山脉，总面积 $252 \mathrm{~km}^{2}$, 由古田山国家级自然保护区、钱江源国家森林公 园、钱江源省级风景名胜区及保护地间的连接地带 组成。该公园地处亚热带季风气候区, 年平均气温 $15.3^{\circ} \mathrm{C}$, 年平均降水量 $1,963.7 \mathrm{~mm}$, 年平均降水天 数 142.5 天, 无霜期 250 天(于明坚等, 2001)。植被类 型沿海拔从低到高依次为常绿润叶林(300-800 m)、 常绿落叶阔叶混交林(800-950 m)、针阔叶混交林 $(950-1,110 \mathrm{~m})$ 、针叶林 $(1,110 \mathrm{~m}$ 以上) (于明坚等, 2001)。土壤类型沿海拔由低到高依次为红壤 (500-700 m)、黄工 壤(700-1,000 m)、红黄襄 $(1,000 \mathrm{~m}$ 以上), 古田庙、石耳山庙低洼处则为山地草甸土(楼 炉焕和金水虎, 2000)。

\section{2 标本采集、鉴定和数据处理}

作者先后赴钱江源国家森林公园和古田山国 家级自然保护区，以及连接上述自然保护地之间的 自然和文化区域，包括苏庄镇、长虹乡、何田乡、 齐溪镇内生境保存较为完好、可能存在叶附生苔的 多个地点进行采集调查, 力求全面覆盖钱江源国家 公园, 共获得新鲜叶附生苔标本41份。所有凭证标 本存放在华东师范大学生物博物馆(HSNU)。

选择比较的 8 个地区都位于 $29^{\circ} 20^{\prime} \mathrm{N}$ 附近 $\left(28^{\circ} 20^{\prime}-30^{\circ} 20^{\prime} \mathrm{N}\right)$, 它们的地名和数据来源分别是 西藏墨脱(吴鹏程和罗健馨, 1978)、安徽南部(刘仲
苓等, 1988)、江西官山(季梦成等, 2005)、江西九岭 幕阜山(季梦成和刘仲苓，1998)、湖南张家界(李登 科, 1990)、湖北后河(彭丹等, 2002)、浙江西天目山 (Tang et al, 2018)、浙江九龙山(刘仲苓, 1986)(表1)。 这 8 个地区的叶附生苔区系在比较前依据最新的世 界苔类植物分类系统(Söderström et al, 2016)和其他 最新的分类处理作更新。物种的中文名主要依据

《中国生物物种名录：苔藓植物》(贾渝和何思, 2013)。

不同地区间种相似性系数 (Sc) 根据Czechanowski系数(张镱锂, 1998)计算, 即:

$S_{C}=\frac{\text { 甲乙两地共有种的数目 } \times 2}{\text { 甲地所有种的数目飞地所有种的数目 }} \times 100 \%$

\section{结果}

2.1 钱江源国家公园叶附生苔区系组成和特点

通过对获得标本的鉴定，共获得4科9属19种, 新增3科8属17种(表1, 附录1, 附录2)。19种叶附生 苔全部属于叶苔纲，其中仅平叉苔(Metzgeria conjugata)属于叉苔目的叉苔科, 其余18种均属于光颌 苔目，包括细鳞苔科(16种)、耳叶苔科(1种)、扁萝 苔科(1种)。

在19种叶附生苔中有16种隶属于细鳞苔科, 因 此细鳞苔科为该地区的优势科。有 9 种属于疮鳞苔 属，故病鳞苔属为该地区叶附生苔区系的优势属。 鳞叶疮鳞苔(Cololejeunea longifolia) (图1)和尖叶薄 鳞苔(Leptolejeunea subacuta) 在公园内多个地点均 有分布，是钱江源国家公园最常见种(附录2)。

与我国同纬度其他 8 个叶附生苔分布点相比(表 1), 钱江源国家公园的叶附生苔种类独特, 共有7种 仅在该地区分布, 分别是距齿疮鳞苔(Cololejeunea macounii)、短肋疮鳞苔 (C. subfloccosa)、疮瓣疮鳞 苔(C. subkodamae)、丛生角鳞苔(Drepanolejeunea commutata)、日本角鳞苔 $(D$. e erecta $)$ 、日本细鳞苔 (Lejeunea japonica) 和疏叶纤鳞苔 (Microlejeunea ulicina)。其余12个种在同纬度其他地区也有分布 (表1)。

根据叶附生苔在各种基质的出现情况，可分为 专性附生(obligate epiphyllous liverworts)、兼性常见 (facultative, common epiphyllous liverworts)、兼性偶 见(occasional epiphyllous liverworts) 3种类型(Zhu et al, 1998; Zhu \& So, 2001)。钱江源国家公园的叶附 

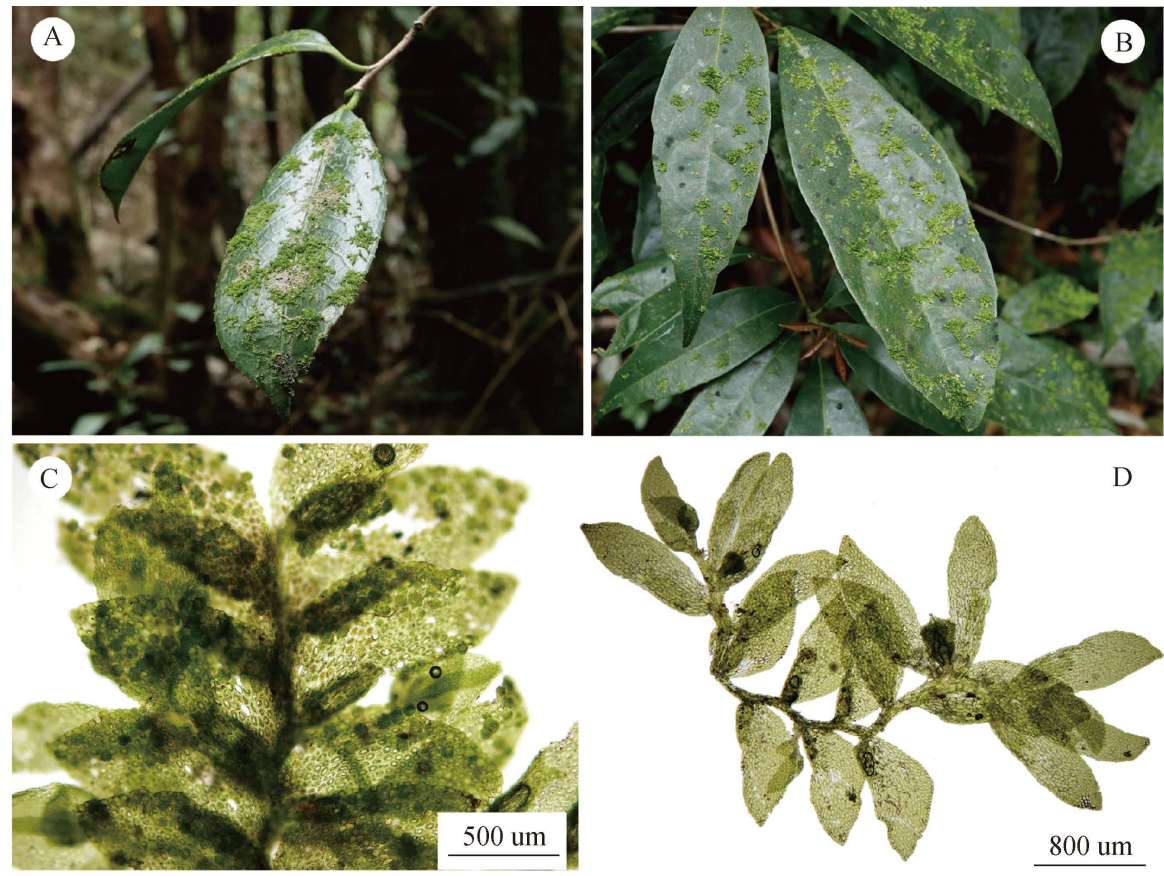

图1 鳞叶病鳞苔。A和B: 生境; C和D: 植物体的一部分 $(C$, 具有无数的芽胞, 背面观; D, 腹面观)。 $A$ 和 $C$ 摄自朱瑞良等 20190413-75, B和D摄自朱瑞良等20190413-92。

Fig. 1 Cololejeunea longifolia. A, B: Growth habit in the wild; C, D: Portion of plant (C, with numerous gemmae, dorsal view; D, ventral view). A and C from Zhu et al 20190413-75; B and D from Zhu et al 20190413-92.

生苔中，兼性偶见的有列胞耳叶苔(Frullania monil$i a t a)$ 和平叉苔, 而其余17种为兼性常见。专性附生 叶附生苔的缺乏可能是由于钱江源国家公园的温 湿条件还无法达到热带雨林的水平。

钱江源国家公园叶附生苔分布海拔普遍较低。 在41份标本中有39份于海拔300-500 m区间内采得, 属于公园内的常绿阔叶林带。41份标本中只有日本 角鳞苔和疏叶纤鳞苔 2 个种采集于海拔 $850 \mathrm{~m}$ 处, 在 常绿落叶阔叶混交林带内。叶附生苔分布较为集 中, 主要分布在古田山自然保护区的原始森林、齐 溪片区枫楼坑以及钱江源国家森林公园，前两个地 方分别有 8 种和 9 种, 钱江源国家森林公园有 3 种。这 三处均树木茂盛、有溪流经过，且受人类干扰较少， 在光照、湿度等方面为叶附生苔的生长创造了优良 条件。

\section{2 钱江源国家公园与同纬度其他地区的叶附生} 苔比较

钱江源国家公园叶附生苔种类多样，属和种的 数目仅次于西藏墨脱, 位列我国同纬度地区第二 (附录3)。刘仲苓等(1988)曾报道皖南有17种叶附生 苔, 其中卵舌片鳞苔(Pedinolejeunea aoshimensis)和 粗齿片鳞苔 $(P$. planissima $)$ 均被归并为粗齿疮鳞苔
(Cololejeunea planissima), 故皖南地区现有叶附生 苔4科8属16种。

从附录4可知, 钱江源国家公园的叶附生苔区 系与江西官山、皖南祁门和江西九岭幕阜山的亲缘 关系最近, 其他依次是湖北后河和西藏墨脱, 与湖 南张家界、浙江西天目山和浙江九龙山的种相似性 系数较低。

\section{3 钱江源国家公园叶附生苔的附主植物}

经过对 41 份标本的鉴定, 发现钱江源国家公园 的叶附生苔主要生长在阔叶箬竹 (Indocalamus latifolius)、珍珠莲(Ficus sarmentosa var. henryi)、络 石(Trachelospermum jasminoides)等被子植物的叶片 上(详细名录见附录1)。其中阔叶箬竹和珍珠莲是该 公园最受喜爱的两种附主植物, 分别有 9 种和 5 种叶 附生苔附生在这两种被子植物上。

\section{3 讨论}

叶附生苔主要分布在赤道南北纬 $30^{\circ}$ 之间, 包 括亚洲、澳大利亚、非洲、美洲和欧洲的马卡罗尼 西亚群岛, 在高纬度地区也有零星记录(Jiang et al, 2018)。我国有叶附生苔168种, 隶属于10科28属, 其 中海南、台湾、浙江西南部和福建北部、云南南部、 
表1 钱江源国家公园叶附生苔在其他同纬度地区的分布

Table 1 Distribution of epiphyllous liverworts in the same latitude in Qianjiangyuan National Park

\begin{tabular}{|c|c|c|c|c|c|c|c|c|c|}
\hline 物种 & 浙江钱江源 & 西藏墨脱 & 安徽南部 & 江西官山 & 江西九岭 & 湖南张家界 & 湖北后河 & 浙江西天目山 & 浙江九龙山 \\
\hline Species & $\begin{array}{l}\text { Qianjiangyuan, } \\
\text { Zhejiang }\end{array}$ & $\begin{array}{l}\text { Motuo, } \\
\text { Xizang }\end{array}$ & $\begin{array}{l}\text { Southern } \\
\text { Anhui }\end{array}$ & $\begin{array}{l}\text { Guanshan, } \\
\text { Jiangxi }\end{array}$ & $\begin{array}{l}\text { 幕阜山 } \\
\text { Jiulingmufu- } \\
\text { shan, Jiangxi }\end{array}$ & $\begin{array}{l}\text { Zhangjiajie, } \\
\text { Hunan }\end{array}$ & $\begin{array}{l}\text { Houhe, } \\
\text { Hubei }\end{array}$ & $\begin{array}{l}\text { West } \\
\text { Tianmushan, } \\
\text { Zhejiang }\end{array}$ & $\begin{array}{l}\text { Jiulongshan, } \\
\text { Zhejiang }\end{array}$ \\
\hline
\end{tabular}

Cheilolejeunea

trapezia

\begin{tabular}{|c|c|c|c|c|c|c|c|c|}
\hline $\begin{array}{l}\text { 白边疮鳞苔 } \\
\text { Cololejeunea } \\
\text { inflata }\end{array}$ & + & + & + & + & & & & \\
\hline $\begin{array}{l}\text { 鳞叶疮鳞苔 } \\
\text { Cololejeunea } \\
\text { longifolia }\end{array}$ & + & & + & & + & + & + & + \\
\hline $\begin{array}{l}\text { 距齿病鳞苔 } \\
\text { Cololejeunea } \\
\text { macounii }\end{array}$ & + & & & & & & & \\
\hline $\begin{array}{l}\text { 粗疮鳞苔 } \\
\text { Cololejeunea } \\
\text { peraffinis }\end{array}$ & + & & + & & & & & \\
\hline $\begin{array}{l}\text { 粗齿疮鳞苔 } \\
\text { Cololejeunea } \\
\text { planissima }\end{array}$ & + & + & + & + & + & & & \\
\hline $\begin{array}{l}\text { 刺疮鳞苔 } \\
\text { Cololejeunea } \\
\text { spinosa }\end{array}$ & + & + & & & + & & & + \\
\hline $\begin{array}{l}\text { 短肋疮鳞苔 } \\
\text { Cololejeunea } \\
\text { subfloccosa }\end{array}$ & + & & & & & & & \\
\hline $\begin{array}{l}\text { 疮瓣疮鳞苔 } \\
\text { Cololejeunea } \\
\text { subkodamae }\end{array}$ & + & & & & & & & \\
\hline $\begin{array}{l}\text { 单体疮鳞苔 } \\
\text { Cololejeunea } \\
\text { trichomanis }\end{array}$ & + & + & & & & & & \\
\hline $\begin{array}{l}\text { 从生角鳞苔 } \\
\text { Drepanolejeunea }\end{array}$ & + & & & & & & & \\
\hline
\end{tabular}

\begin{tabular}{|c|c|c|c|c|c|c|c|c|c|}
\hline $\begin{array}{l}\text { 日本角鳞苔 } \\
\text { Drepanolejeunea } \\
\text { erecta }\end{array}$ & + & & & & & & & & \\
\hline $\begin{array}{l}\text { 列胞耳叶苔 } \\
\text { Frullania moniliata }\end{array}$ & + & & & & + & + & & & \\
\hline $\begin{array}{l}\text { 日本细鳞苔 } \\
\text { Lejeunea japonica }\end{array}$ & + & & & & & & & & \\
\hline $\begin{array}{l}\text { 尖叶薄鳞苔 } \\
\text { Leptolejeunea } \\
\text { subacuta }\end{array}$ & + & + & + & + & + & + & + & & + \\
\hline $\begin{array}{l}\text { 平叉苔 } \\
\text { Metzgeria } \\
\text { conjugata }\end{array}$ & + & & & + & & & + & & \\
\hline $\begin{array}{l}\text { 斑叶纤鳞苔 } \\
\text { Microlejeunea } \\
\text { punctiformis }\end{array}$ & + & + & & + & & + & + & + & \\
\hline $\begin{array}{l}\text { 疏叶纤鳞苔 } \\
\text { Microlejeunea } \\
\text { ulicina }\end{array}$ & + & & & & & & & & \\
\hline $\begin{array}{l}\text { 尖舌扁萝苔 } \\
\text { Radula acuminata }\end{array}$ & + & + & + & + & & & + & & \\
\hline
\end{tabular}


云南西北部和西藏东南部为我国叶附生苔的 5 个分 布中心(Zhu \& So, 2001)。钱江源国家公园的叶附生 苔种数在同纬度地区中仅次于西藏墨脱, 名列第二, 是一个值得关注的叶附生苔分布区。同时, 由于叶 附生苔个体微小、生境独特以及分类鉴定的困难, 与钱江源国家公园同纬度的一些保护区也有待开 展更深入的叶附生苔本底调查。浙江九龙山地理位 置比较靠近钱江源国家公园, 但两地的种相似性系 数较低, 这可能与九龙山缺乏较完好的低海拔常绿 阔叶林有关。

与其他苔藓植物相比, 叶附生苔在形态结构和 繁殖方式方面具有明显特点(Zhu \& So, 2001; 姜炎 涁和邵小明，2016)。个体细小而扁平，腹面有束状 假根和卷曲的囊状腹瓣, 有些叶附生苔细胞壁表面 突起形成疮，这些特殊结构大大提高了叶附生苔的 固着、防风、储水、抗旱能力(Zhu \& So, 2001; 姜 炎涁和邵小明，2016)。芽胞 (gemmae)、繁殖枝 (cladia)、脱落的叶等无性繁殖器官极易借助风力水 汽传播, 因此以无性繁殖为主的生殖方式也对叶附 生苔的扩散至关重要(Zhu \& So, 2001)。钱江源国家 公园最常见的鳞叶疮鳞苔和尖叶薄鳞苔都具有独 特的无性繁殖能力, 前者能产丰富的芽胞(图1), 后 者能产生充足的繁殖枝。

陈邦杰和吴鹏程(1964)认为温度和湿度是影响 叶附生苔生长和繁殖的主要因素, Sonnleitner等的 研究表明相对湿度是影响叶附生苔生长最为关键 的因素, 叶附生苔多样性也与光照、温度等因素密 不可分(Sonnleitner et al, 2009; Tang et al, 2018)。钱 江源国家公园地理位置优越, 夏季来自太平洋的湿 暖气流经过白际山脉时遇冷变为降水落在迎风坡, 使该地区夏季湿润、雨水多; 冬季来自西伯利亚的 冷空气被白际山脉阻挡在背风坡, 故该地区冬季温 暖、无霜期长(汪长林, 2018)。年平均气温 $15.3^{\circ} \mathrm{C}$, 年 平均降水量 $1,963.7 \mathrm{~mm}$, 年平均降水天数 142.5 天 (于明坚等, 2001)。钱江源国家公园的气候和合适的 温湿环境, 为叶附生苔的生长繁殖创造了得天独厚 的条件。

林冠层发育良好、干扰少对叶附生苔的生长有 重要影响(姜炎涁和邵小明, 2016)。最近5年来, 随着 生态文明建设的不断深入, 以保护自然生态系统的 原真性、完整性为目的, 钱江源国家公园各乡镇陆 续与安徽省、江西省毗邻区域签订可持续发展协议,
在这片 $252 \mathrm{~km}^{2}$ 的土地上，核心保护区占比 $28.66 \%$, 生态保育区占比 $53.81 \%$, 游㮩展示区占比 $3.22 \%$, 传统利用区占比14.31\% (汪长林，2018)。不断发展 完善的保护措施成就了长江三角洲最后这块生态 处女地, 为世界各地的研究者提供了完整的生态系 统和优良的实践平台(汪长林, 2018)。苔藓植物的保 护也因此获益，完整的植被、茂盛的树木、幽闭的 沟谷大大削弱了光照强度、增加了空气湿度, 为叶 附生苔的生长提供了良好的环境。叶附生苔主要分 布于低海拔的常绿阔叶林和雨林中 (Zhu \& So 2001)。在钱江源国家公园，近90\%的叶附生苔种都 出现在海拔 $500 \mathrm{~m}$ 以下的常绿阔叶林内。与同纬度 的其他地区相比，钱江源国家公园丰富的叶附生苔 无疑与保存完好的低海拔常绿阔叶林有关。

除此之外, 全球气候变暖也可能影响叶附生苔 的分布。在物种分布对气候变化的响应上, 多项研 究预测到未来北半球植物分布区北缘将会继续向 高纬度地区推进(Alsos et al, 2007; Guralnick, 2007), Jiang等(2014)通过模拟发现中国叶附生苔的最北缘 可能到达重庆北部。过去20年里, 34种苔藓植物的 分布区域因温度升高已扩展至中欧(Frahm \& Klaus, 2001), Duckett (2008)甚至在欧洲 $51^{\circ} \mathrm{N}$ 的一个自然 保护区内发现3个叶附生苔记录。加拿大(Vitt et al, 1973)、美国(Risk et al, 2011)等也在纬度较高的地区 发现了叶附生苔的踪影。在我国, Tang等(2018)在纬 度 $30^{\circ} \mathrm{N}$ 以上的浙江西天目山发现了 5 种叶附生苔, 并推测种类的增加可能与全球气候变暖有关。但与 温度相比, 相对湿度是影响叶附生苔生长更为关键 的因素，气候变暖通常也导致空气湿度的下降。气 候变暖是否可能对钱江源国家公园叶附生苔的物 种多样性产生一定影响, 有待对该地叶附生苔长期 的跟踪监测。作者建议在今后的钱江源国家公园以 及其他国家公园和保护区大样地监测中, 增加对气 候变化敏感的叶附生苔的监测。

致谢: 感谢浙江师范大学陈建华教授对叶附生苔附 株植物(种子植物)标本的鉴定以及评审专家和编委 对论文修改提出的宝贵建议。

\section{参考文献}

Alsos IG, Eidesen PB, Ehrich D, Skrede I, Westergaard K, Jacobsen GH, Landvik JY, Taberlet P, Brochmann C (2007) 
Frequent long-distance plant colonization in the changing Arctic. Science, 316, 1606-1609.

Benavides JC, Sastre-De Jesús I (2011) Diversity and rarity of epiphyllous bryophytes in a superhumid tropical lowland forest of Chocó-Colombia. Cryptogamie Bryologie, 32, 119-133.

Chen PC, Wu PC (1964) Study on epiphyllous liverworts of China (I). Acta Phytotaxonomica Sinica, 9, 213-276. (in Chinese with English abstract) [陈邦杰, 吴鹏程 (1964) 中国 叶附生苔类植物的研究(一). 植物分类学报, 9, 213-276.]

Duckett JG (2008) Epiphyllic and epifungal liverworts on Hampstead Heath, London. Field Bryology, 95, 8-10.

Frahm JP, Klaus D (2001) Bryophytes as indicators of recent climate fluctuations in Central Europe. Lindbergia, 26, 97-104.

Guralnick R (2007) Differential effects of past climate warming on mountain and flatland species distributions: A multispecies North American mammal assessment. Global Ecology and Biogeography, 16, 14-23.

Ji MC, Liu ZL (1998) A preliminary report on the epiphyllous liverworts from Jiuling Mufu Mountain of Jiangxi Province, China. Acta Museum Historiae Naturae Sinica, 16, 13-16. (in Chinese with English abstract) [季梦成, 刘仲苓 (1998) 江西九岭幕阜山叶附生苔初报. 自然博物馆学报, 16 , 13-16.]

Ji MC, Zheng G, Xie Y, Wu HP, Qiang S (2005) Epiphyllous liverworts from Guanshan Nature Reserve of Jiangxi Province. Journal of Zhejiang Forestry College, 22, 370-374. (in Chinese with English abstract) [季梦成, 郑钢, 谢云, 吴和 平, 强胜 (2005) 江西省官山自然保护区叶附生苔类植 物. 浙江林学院学报, 22, 370-374.]

Jia Y, He S (2013) Species Catalogue of China: Bryophytes. Science Press, Beijing. (in Chinese) [贾渝, 何思 (2013) 中 国生物物种名录: 苔藓植物. 科学出版社, 北京.]

Jiang YB, Shao XM (2016) Diversity and distribution pattern of epiphyllous liverworts and its ecological determinants. Chinese Journal of Plant Ecology, 40, 523-532. (in Chinese with English abstract) [姜炎森, 邵小明 (2016) 叶附生苔 植物物种多样性分布格局及生态成因. 植物生态学报, 40, 523-532.]

Jiang YB, Wang TJ, de Bie CAJM, Skidmore AK, Liu XH, Song SS, Zhang L, Wang J, Shao XM (2014) Satellite- derived vegetation indices contribute significantly to the prediction of epiphyllous liverworts. Ecological Indicators, 38, 72-80.

Jiang YB, Wang TJ, Wu YP, Hu RG, Huang K, Shao XM (2018) Past distribution of epiphyllous liverworts in China: The usability of historical data. Ecology and Evolution, 8, 7436-7450.

Li DK (1990) Preliminary reprot [sic] on the epiphyllous liverworts in Human [sic] Province, China. Investigatio et Studium Naturae, 10, 137-138. (in Chinese with English abstract) [李登科 (1990) 湖南省叶附生苔初报. 考察与
研究, 10, 137-138.]

Liu ZL (1986) A preliminary study of Hepaticae from Mt. Jiulongshan, Prov. Zhejiang, Eastern China. Investigatio et Studium Naturae, 5, 133-152. (in Chinese with English abstract) [刘仲苓 (1986) 浙江九龙山苔类植物的初步研 究. 考察与研究, 5, 133-152.]

Liu ZL, Guo XH, Hu RL (1988) Investigation on the epiphyllous liverworts from southern part of Anhui Prov., East China. Journal of East China Normal University (Natural Science), (4), 89-96. (in Chinese with English abstract) [刘 仲苓, 郭新弧, 胡人亮 (1988) 皖南叶附生苔研究一一安 徽苔藓植物区系研究之一. 华东师范大学学报(自然科学 版), (4), 89-96.]

Lou LH, Jin SH (2000) Spermatophyta flora of Gutianshan Nature Reserve in Zhejiang. Journal of Beijing Forestry University, 22(5), 33-39. (in Chinese with English abstract) [楼炉焕, 金水虎 (2000) 浙江古田山自然保护区种子植 物区系分析. 北京林业大学学报, 22(5), 33-39.]

Peng D, Liu SX, Wu PC (2002) Studies on the epiphyllous liverworts of China VIII - The epiphyllous liverworts of Houhe National Nature Reserve. Journal of Wuhan Botanical Research, 20, 199-201. (in Chinese with English abstract) [彭丹, 刘胜祥, 吴鹏程 (2002) 中国叶附生苔类植 物的研究(八)——湖北后河自然保护区的叶附生苔类. 武汉植物学研究, 20, 199-201.]

Risk AC, Richardson C, Davison P (2011) Epiphyllous bryophytes in the Appalachian Plateau of Kentucky and Tennessee, U. S. A. The Bryologist, 114, 289-297.

Söderström L, Hagborg A, von Konrat M, BartholomewBegan S, Bell D, Briscoe L, Brown E, Cargill DC, Costa DP, Crandall-Stotler BJ, Cooper ED, Dauphin G, Engel JJ, Feldberg K, Glenny D, Gradstein SR, He XL, Ilkiu-Borges AL, Heinrichs J, Hentschel J, Katagiri T, Konstantinova NA, Larraín J, Long DG, Nebel M, Pócs T, Puche F, Reiner-Drehwald E, Renner MAM, Sass-Gyarmati A, Schäfer-Verwimp A, Segarra-Moragues JG, Stotler RE, Sukkharak P, Thiers BM, Uribe J, Váňa J, Villarreal JC, Wigginton M, Zhang L, Zhu RL (2016) World checklist of hornworts and liverworts. PhytoKeys, 59, 1-828.

Sonnleitner M, Dullinger S, Wanek W, Zechmeister H (2009) Microclimatic patterns correlate with the distribution of epiphyllous bryophytes in a tropical lowland rain forest in Costa Rica. Journal of Tropical Ecology, 25, 321-330.

Tang X, Gradstein SR, Sun LW, Zhu MJ, Shi RP, Wei QQ, Chen YQ, Zhou XX, Wang J (2018) A contribution to the knowledge of epiphyllous bryophytes in Tianmushan National Nature Reserve (Zhejiang, China), with remarks on climate warming and nature conservation. Lindbergia, 41, $1-7$.

Tian CY, Wu JQ, Liu SX, Hu RL (1999) Characteristics of the bryoflora of Gutianshan Nature Reserve in Kaihua County, Zhejiang Province and comparisons of the bryoflora of the nature reserve and several other nearby mountain areas. 
Journal of Wuhan Botanical Research, 17, 146-152. (in Chinese with English abstract) [田春元, 吴金清, 刘胜祥, 胡人亮 (1999) 浙江古田山自然保护区苔藓植物区系特 点及其与邻近山体的比较. 武汉植物学研究, 17 , 146-152.]

Vitt DH, Ostafichuk M, Brodo IM (1973) Foliicolous bryophytes and lichens of Thuja plicata in western British Columbia. Canadian Journal of Botany, 51, 571-580.

Wang CL (2018) Qianjiangyuan National Park. Xiling Seal Engraver's Society Publishing House, Hangzhou. (in Chinese) [汪长林 (2018) 钱江源国家公园. 西泠印社出版社, 杭州.]

Wu PC, Lou JS (1978) Studies on the epiphyllous liverworts of China (II )-The epiphyllous liverworts from Tibet. Acta Phytotaxonomica Sinica, 16, 102-112. (in Chinese with English abstract) [吴鹏程, 罗健馨 (1978) 中国叶附生苔 类植物的研究(二)一一西藏的叶附生苔. 植物分类学报, 16, 102-112.]

Yu MJ, Hu ZH, Yu JP, Ding BY, Fang T (2001) Forest vegetation types in Gutianshan Natural Reserve in Zhejiang. Journal of Zhejiang University (Agriculture and Life Sciences), 27, 375-380. (in Chinese with English abstract) [于明坚, 胡正华, 余建平, 丁炳扬, 方腾 (2001) 浙江古 田山自然保护区森林植被类型. 浙江大学学报(农业与生 命科学版), 27, 375-380.]

Zhang YL (1998) Coefficient of similarity-An important parameter in floristic geography. Geographical Research, 17, 429-434. (in Chinese with English abstract) [张镱锂 (1998) 植物区系地理研究中的重要参数——相似性系 数. 地理研究, 17, 429-434.]

Zhu RL, So ML (2001) Epiphyllous liverworts of China. Nova Hedwigia Beiheft, 121, 1-418.

Zhu RL, So ML, Ye LX (1998) A synopsis of the hepatic flora of Zhejiang, China. Journal of the Hattori Botanical Laboratory, 84, 159-174.

(责任编委: 严岳鸿 责任编辑: 时意专)

\section{附录 Supplementary Material}

附录1 钱江源国家公园叶附生苔类植物名录

Appendix 1 A checklist of epiphyllous liverworts of the Qianjiangyuan National Park http://www.biodiversity-science.net/fileup/PDF/2019273-1.pdf

附录2 钱江源国家公园叶附生苔类植物的显微照片

Appendix 2 Photomicrographs of epiphyllous liverworts of the Qianjiangyuan National Park

http://www.biodiversity-science.net/fileup/PDF/2019273-2.pdf

\section{附录3 我国 $29^{\circ} 20^{\prime} \mathrm{N}$ 附近9个地区的叶附生苔统计}

Appendix 3 Number of epiphyllous liverworts in nine areas near $29^{\circ} 20^{\prime} \mathrm{N}$ in China

http://www.biodiversity-science.net/fileup/PDF/2019273-3.pdf

\section{附录4 钱江源国家公园与同纬度地区叶附生种的相似性系数}

Appendix 4 Coefficient of similarity of epiphyllous species between Qianjiangyuan National Park and other areas of China with the same latitude

http://www.biodiversity-science.net/fileup/PDF/2019273-4.pdf 